\title{
DEK promotes the proliferation and invasion of lung cancers and indicates poor prognosis in lung adenocarcinomas
}

\author{
MAI-QING YANG ${ }^{1,2}$, LIN-LIN BAI ${ }^{3}$, LEI LEI ${ }^{1}$, YI-WEN ZHENG ${ }^{1}$, ZHAO WANG $^{1,4}$, \\ ZHI-HAN LI ${ }^{1}$, CHEN-CHEN LIU ${ }^{1}$, WEN-JING HUANG ${ }^{1}$ and HONG-TAO XU ${ }^{1}$ \\ ${ }^{1}$ Department of Pathology, The First Hospital and College of Basic Medical Sciences of China Medical University, \\ Shenyang, Liaoning 110001; ${ }^{2}$ Department of Pathology, Changyi People's Hospital, Changyi, Shandong 261300; \\ ${ }^{3}$ Department of Pathology, Shenyang 242 Hospital, Shenyang, Liaoning 110001; ${ }^{4}$ Department of Pathology, \\ General Hospital of Heilongjiang Land Reclamation Bureau, Harbin, Heilongjiang 150000, P.R. China
}

Received October 20, 2019; Accepted January 10, 2020

DOI: 10.3892/or.2020.7488

\begin{abstract}
DEK has been revealed to be overexpressed in many cancers and associated with cancer progression. The aim of the present study was to elucidate the role of DEK with a specific focus on its underlying mechanism in lung cancers. DEK expression in lung cancers and normal lung tissues and the correlations between DEK expression and clinicopathological parameters of lung cancers were investigated using the data from The Cancer Genome Atlas (TCGA). DEK expression was upregulated by $D E K$ transfection or downregulated by $D E K$ shRNA interference in A549 and H1299 cells. The effects of DEK on the Wnt signaling pathway and epithelial-mesenchymal transition (EMT) were examined using western blotting. Proliferative and invasive abilities were observed in A549 and H1299 cells treated with DEK using an MTT assay, colony formation assay, and Transwell migration and invasion assays. The expression of DEK was higher in lung cancer tissues than that in normal lung tissues. DEK expression was positively correlated with the expression of epidermal growth factor receptor (EGFR) and KRAS in
\end{abstract}

Correspondence to: Dr Hong-Tao Xu, Department of Pathology, The First Hospital and College of Basic Medical Sciences of China Medical University, Shenyang, Liaoning 110001, P.R. China E-mail: xuht@cmu.edu.cn

Abbreviations: TCGA, The Cancer Genome Atlas; LUAD, lung adenocarcinoma; LUSC, lung squamous cell carcinoma; NSCLC, non-small cell lung cancer; SCLC, small-cell lung cancer; HIV, human immunodeficiency virus; EMT, epithelial-mesenchymal transition; EGFR, epidermal growth factor receptor; ALK, anaplastic lymphoma kinase; KRAS, Kirsten rat sarcoma viral oncogene homolog; ROS, tyrosine-protein kinase; MMP, matrix metalloproteinase; DVL, dishevelled homolog; TCF, transcription factor; LRP, low-density lipoprotein receptor-related protein; Gsk, glycogen synthase kinase; APC, adenomatous polyposis coli

Key words: DEK, lung cancer, prognosis, Wnt signaling pathway, EMT lung adenocarcinomas. High expression of DEK indicated poor prognosis in lung adenocarcinomas $(\mathrm{P}=0.018)$. Enhanced expression of DEK upregulated the levels of active- $\beta$-catenin and Wnt target genes, such as cyclin D1, c-Myc and MMP7 and increased the proliferative and invasive abilities of lung cancer cells. Enhanced expression of DEK in A549 and H1299 cells also increased the levels of EGFR, KRAS, vimentin, Snail, and $\mathrm{N}$-cadherin, and decreased the level of E-cadherin. The opposite results were obtained with knockdown of DEK expression. DEK was highly expressed in lung cancers and indicated poor prognosis in lung adenocarcinomas. DEK expression activated the Wnt signaling pathway and EMT process and promoted the proliferation and invasion of lung cancers.

\section{Introduction}

Lung cancer is one of the most prevalent and aggressive malignancies, and is a major cause of cancer-related deaths in the world, having the highest incidence and mortality rate among all cancers (1). Lung cancer is routinely classified as non-small cell lung cancer (NSCLC) and small-cell lung cancer (SCLC), and the former accounts for approximately $80-85 \%$ of all lung cancers. Only $17.7 \%$ of the patients who are diagnosed with lung cancer live more than 5 years. Most patients with NSCLC are diagnosed in the advanced stages, and the overall 5-year survival rate is low due to its recurrence and metastasis (2-6). Therefore, there is an urgent need to explore the mechanisms of NSCLC and to find effective biomarkers for prognostic evaluation and therapy.

$D E K$ is a potential biomarker and oncogene, which is reported in many cancers (7-9). The $D E K$ gene encodes the DEK oncoprotein with one SAP domain which binds to cruciform and superhelical DNA to then influence various important nuclear processes, such as transcriptional regulation, signal transduction, differentiation, apoptosis, RNA processing and DNA replication (10-16). Increased expression of DEK has been revealed to be associated with various neoplasms, including breast, cervical, and neuroendocrine prostate cancer, hematologic malignancies, gastric adenocarcinoma, and lung cancer $(8,17-23)$. DEK was revealed to promote epithelial-mesenchymal transition (EMT) and angiogenesis 
by activating the PI3K/AKT/mTOR pathway in triple negative breast cancers (8). Depletion of DEK suppressed the proliferation, migration, invasion, and angiogenesis of breast cancer cells (8). The silencing of DEK induced apoptosis and senescence via the upregulation of $\mathrm{NF}-\kappa \mathrm{B}(23)$ and downregulated tumorigenesis and metastasis by the $\mathrm{DEK} / \mathrm{Gsk} 3 \beta / \beta$-catenin axis in cervical cancer cells (22). In acute myelogenous leukemia, DEK was involved in chromosomal translocation by binding to the HIV-2 enhancer (11). In neuroendocrine prostate cancer and gastric adenocarcinoma, increased DEK expression was revealed to be an independent clinical risk factor and associated with shorter disease-free survival of cancer patients $(9,21)$. These findings indicated that DEK may be a potential biomarker and predicator for tumor progression and therapy. However, the role and underlying mechanism of DEK in lung cancer has been poorly explored.

In the present study, the expression data for DEK in lung cancers was collected and the correlations between DEK expression and clinicopathological parameters of lung cancers was analyzed. The role of DEK in the proliferation and invasion of lung cancer cells was also investigated and the effects of DEK on the Wnt signaling pathway and EMT process were explored.

\section{Materials and methods}

The cancer genome atlas (TCGA) data collection and analysis. The expression data of DEK in lung cancers and normal lung tissues, and the correlations between DEK expression and prognosis of lung cancers were obtained and analyzed using the online databases Gene Expression Profiling Interactive Analysis (GEPIA; http://gepia.cancer-pku.cn) and UALCAN (http://ualcan.path.uab.edu) (24), which is based on The Cancer Genome Atlas (TCGA).

Cell lines and transfection. All the cell lines used in the present study were purchased from the Cell Bank of the Chinese Academy of Sciences (Shanghai, China). The normal human bronchial epithelial (HBE) cell line was cultured in minimal essential medium (Gibco; Invitrogen; Thermo Fisher Scientific, Inc.), and the human lung cancer cell lines A549, H1299, SK-MES-1, LK2, H460 and H661 were cultured in RPMI-1640 medium (Gibco; Invitrogen; Thermo Fisher Scientific, Inc.). Both culture mediums contained $10 \%$ fetal bovine serum (FBS) (FB15015; Clark Bioscience). All these cells were maintained at $37^{\circ} \mathrm{C}$ in an atmosphere containing $5.0 \%$ carbon dioxide (25-27).

A549 and H1299 cells were plated in 6-well plates for $24 \mathrm{~h}$ and cultured to $70-80 \%$ confluence before gene transfection. The plasmids contained the $D E K$ or DEK-shRNA sequences that were synthesized by Shanghai GeneChem Co., Ltd. The plasmids were transfected into cells using Lipofectamine 3000 (Invitrogen; Thermo Fisher Scientific, Inc.), according to the manufacturer's protocol. An empty vector or a plasmid that contained a scrambled shRNA sequence served as a negative control for the plasmid of $D E K$ or $D E K$-shRNA, respectively.

Western blot analysis. The total protein extracted from each sample was separated by cell lysis buffer (Pierce; Thermo Fisher Scientific, Inc.) and quantified using the Bradford method. Totally, $60 \mu \mathrm{g}$ of protein was separated by SDS-PAGE $(10 \%)$ and transferred to a polyvinylidene fluoride membrane (EMD Millipore). The bands were blocked in 5\% non-fat milk for $1 \mathrm{~h}$ at room temperature. The membranes were incubated with primary antibodies (Table I) overnight at $4{ }^{\circ} \mathrm{C}$ and then washed with tris-buffered saline containing $0.1 \%$ Tween-20. The membranes were incubated with an anti-rabbit or anti-mouse IgG antibody (1:2,000; ProteinTech Group, Inc.) conjugated with horseradish peroxidase (BIOSS) at $37^{\circ} \mathrm{C}$ for $2 \mathrm{~h}$. Finally, the membranes were visualized using an enhanced chemilumiscence reagent (Pierce; Thermo Fisher Scientific, Inc.) and detected with a bioimaging system (DNR Bio-Imaging System). The blots were stripped according to the manufacturer's protocol using a stripping buffer (Beyotime Institute of Biotechnology) and the bands that had similar/the same molecular weight were re-probed. The relative protein levels were analyzed with ImageJ software (version 1.47; National Institutes of Health) using GAPDH as a loading control.

Colony forming assay. Cells were plated in 6-well plates by seeding 1,000 cells/well $24 \mathrm{~h}$ after transfection and cultured for 14 days. The medium was changed every 4 days. Then, the plates were washed with phosphate-buffered saline (PBS). The cells were fixed with $4 \%$ paraformaldehyde for $20 \mathrm{~min}$ and stained with hematoxylin for $10 \mathrm{~min}$ at $37^{\circ} \mathrm{C}$. The number of colonies formed with more than 50 cells were counted using a BioImaging system.

Cell proliferation assay. Twenty-four hours after transfection, the cells were plated into 96-well plates at a density of 3,000 cells/well in medium containing $10 \% \mathrm{FBS}$. The quantitation of cell viability was detected using Cell Counting Kit-8 (CCK-8; Dojindo Molecular Technologies, Inc.). Each well was supplemented with $\mathrm{CCK}-8$ reagent at 1:10 (v/v) per $100 \mu \mathrm{l}$ and incubated for $2 \mathrm{~h}$ at $37^{\circ} \mathrm{C}$. The data were quantitated spectrophotometrically with a test wavelength of $450 \mathrm{~nm}$.

Cell migration and invasion analyses. Cell migration and invasion assays were performed in 24-well Transwell chambers containing inserts with a pore size of $8 \mu \mathrm{m}$ (Costar Corporation). For Matrigel invasion assays, the upper side of an $8-\mu \mathrm{m}$ pore was coated with Matrigel basement membrane matrix (1:8 dilution; BD Biosciences) for at least $2 \mathrm{~h}$ at $37^{\circ} \mathrm{C}$. After gelation of the Matrigel, the cells were seeded $\left(1 \times 10^{5}\right.$ cells/well) to the upper chambers of a $100-\mu 1$ medium supplemented with $2 \% \mathrm{FBS}$, and the lower chambers were filled with $600 \mu 120 \%$ FBS as the chemoattractant. For the migration assays, the upper chambers were filled with $100 \mu \mathrm{l}$ of medium supplemented with $2 \%$ FBS not-coated with Matrigel, and the lower chambers were filled with $600 \mu 120 \% \mathrm{FBS}$ as a chemoattractant. After $20 \mathrm{~h}$, the filters were fixed with $4 \%$ paraformaldehyde and stained with hematoxylin for $10 \mathrm{~min}$ at $37^{\circ} \mathrm{C}$. The non-invading cells on the upper surface were cleared with a cotton swab. Ten randomly selected high-power fields were observed under light microscopy (magnification, x200), and the number of migrated or invaded cells was counted. All the experiments aforementioned were performed in triplicate independently. 
Table I. List of antibodies used for western blotting.

\begin{tabular}{llccc}
\hline Antibody name & \multicolumn{1}{c}{ Source } & Catalog number & Host & Dilution \\
\hline DEK & ProteinTech Group, Inc. & $16448-1-$ AP & Rabbit & $1: 2,000$ \\
GSK3 $\beta$ & Cell Signaling Technology, Inc. & 5676 & Rabbit & $1: 1,000$ \\
Axin & Santa Cruz Biotechnology, Inc. & SC-293109 & Mouse & $1: 100$ \\
$\beta$-catenin & BD Biosciences & MAB13291 & Rabbit & $1: 1,000$ \\
Active $\beta$-catenin & BD Biosciences & 5279 & Rabbit & $1: 1,000$ \\
c-Myc & BD Biosciences & MAB3696 & Rabbit & $1: 1,000$ \\
MMP7 & Santa Cruz Biotechnology, Inc. & SC-515703 & Mouse & $1: 100$ \\
Cyclin D1 & Santa Cruz Biotechnology, Inc. & SC-8396 & Rabbit & $1: 100$ \\
DVL1 & Santa Cruz Biotechnology, Inc. & SC-8026 & Mouse & $1: 100$ \\
LRP6 & Santa Cruz Biotechnology, Inc. & SC-25317 & Mouse & $1: 100$ \\
LEF1 & Santa Cruz Biotechnology, Inc. & SC-374522 & Mouse & $1: 100$ \\
TCF4 & Santa Cruz Biotechnology, Inc. & SC-166699 & Mouse & $1: 100$ \\
Snail & Cell Signaling Technology, Inc. & 3879 & Rabbit & $1: 500$ \\
Vimentin & Cell Signaling Technology, Inc. & 5741 & Rabbit & $1: 1,000$ \\
E-cadherin & Cell Signaling Technology, Inc. & 3195 & Rabbit & $1: 1,000$ \\
N-cadherin & Cell Signaling Technology, Inc. & 13116 & Rabbit & $1: 1,000$ \\
EGFR & ProteinTech Group, Inc. & $18986-1-A P$ & Rabbit & $1: 1,000$ \\
KRAS & ProteinTech Group, Inc. & $12063-1-A P$ & Rabbit & $1: 1,000$ \\
ALK & ProteinTech Group, Inc. & $24184-1-A P$ & Mouse & $1: 1,000$ \\
GAPDH & Santa Cruz Biotechnology, Inc. & SC-47724 & Rabbit & $1: 1,000$ \\
\hline
\end{tabular}

EGFR, epidermal growth factor receptor; KRAS, Kirsten rat sarcoma viral oncogene homolog; ALK, anaplastic lymphoma kinase.

Statistical analysis. Statistical analyses were performed using statistical software GraphPad Prism 6.0 (GraphPad Software, Inc.). The results were analyzed using Student's t-test, Spearman's rank correlation, and Kaplan-Meier analysis. A $\mathrm{P}<0.05$ was considered to indicate a statistically significant difference.

\section{Results}

DEK expression is higher in lung cancers than in normal lung tissues and correlated with poor prognosis of lung adenocarcinomas. The expression data of DEK in lung cancers and normal lung tissues were analyzed using the online database GEPIA, UALCAN based on TCGA. The data from UALCAN revealed that the expression level of DEK in lung adenocarcinomas $(\mathrm{LUAD})(\mathrm{P}<0.01)$ and lung squamous cell carcinomas (LUSC) $(\mathrm{P}<0.01)$ was significantly higher than that in normal lung tissues (Fig. 1A and B). According to the Kaplan-Meier graph obtained from the GEPIA database, LUAD patients with increased expression of DEK had significantly shorter overall survival $(\mathrm{P}=0.018$, Fig. $1 \mathrm{C})$. However, the expression of DEK was not correlated with the survival of LUSC patients ( $\mathrm{P}=0.97$, Fig. 1D).

DEK promotes the proliferation, colony formation, migration, and invasion of lung cancer cells. The expression levels of DEK in normal HBE and NSCLC cell lines A549, H1299, SK, LK2, H460, and H661 were examined and are revealed in the Fig. S1. DEK was expressed at a relatively low level in A549, H460 and LK2 cells, a moderate level in HBE and
H1299 cells, and a high level in H661 and SK-MES-1 cells. We selected A549 and H1299 for further experiments.

Overexpression of DEK by $D E K$ transfection enhanced the proliferation rate (H1299-DEK, $\mathrm{P}<0.05$; A549-DEK, $\mathrm{P}<0.05)$ and the ability of colony formation (H1299-DEK, $\mathrm{P}<0.05$; A549-DEK, $\mathrm{P}<0.05)$ of H1299-DEK and A549-DEK cells compared to the control cells (Fig. 2). In contrast, knockdown of DEK expression by shRNA inhibited the cellular proliferation rate $(\mathrm{H} 1299$-shDEK, $\mathrm{P}<0.05$; A549-shDEK, $\mathrm{P}<0.05)$ and the ability of colony formation of cells (H1299-shDEK, $\mathrm{P}<0.05$; A549-shDEK, P<0.05) of H1299-shDEK and A549-shDEK, compared to the control cells (Fig. 2).

Furthermore, enhanced DEK expression promoted the migrative and invasive abilities of A549-DEK and H1299-DEK cells compared with the control cells $(\mathrm{P}<0.05$, respectively). Conversely, knockdown of DEK expression inhibited the migrative and invasive abilities of H1299-shDEK and A549-shDEK cells ( $\mathrm{P}<0.01$, respectively) (Fig. 3).

DEK upregulates the activities of $\beta$-catenin and the Wnt signaling pathway. Enhanced DEK expression promoted an increase in the expression levels of active- $\beta$-catenin and LEF1 and inhibited the levels of Gsk $3 \beta$ and Axin in H1299-DEK and A549-DEK cells ( $\mathrm{P}<0.05$ in both cases). The expression levels of some target genes of the Wnt pathway, such as cyclin D1, c-Myc, and $M M P 7$, were also significantly increased in H1299-DEK and A549-DEK cells ( $\mathrm{P}<0.05$ in both cases). However, the levels of total $\beta$-catenin, DVL1, LRP6 and TCF4 were not markedly altered ( $\mathrm{P}>0.05$ ) (Fig. 4A-C). Conversely, knockdown of DEK expression downregulated the levels of 
A

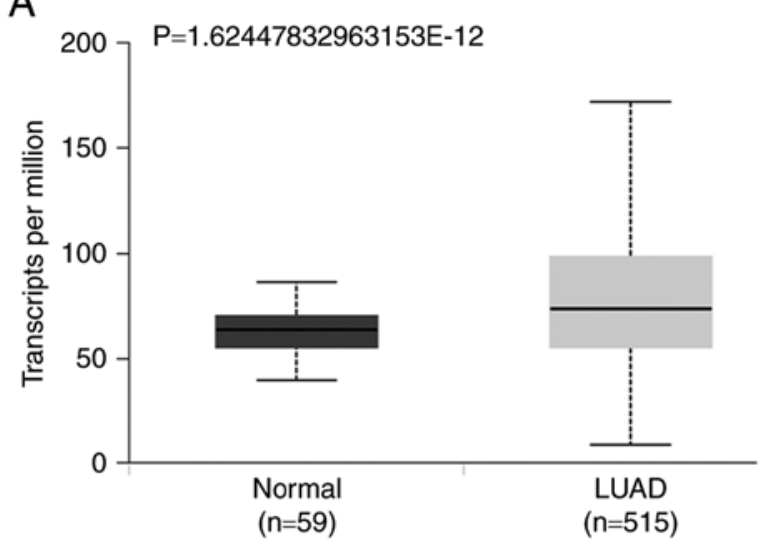

C

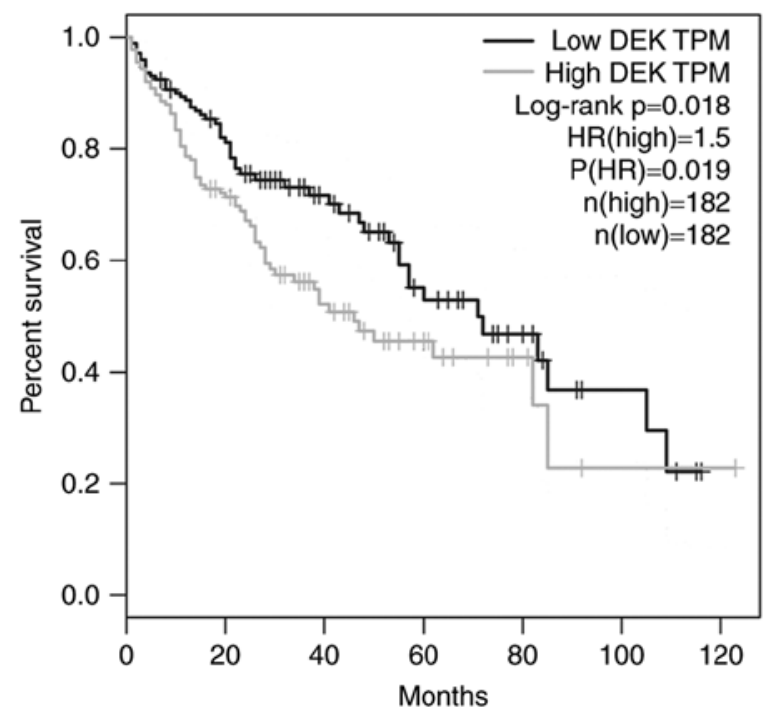

B

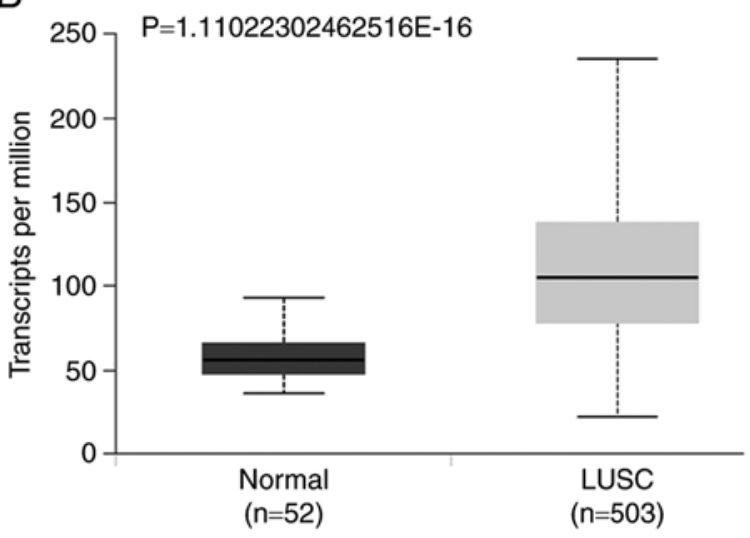

D

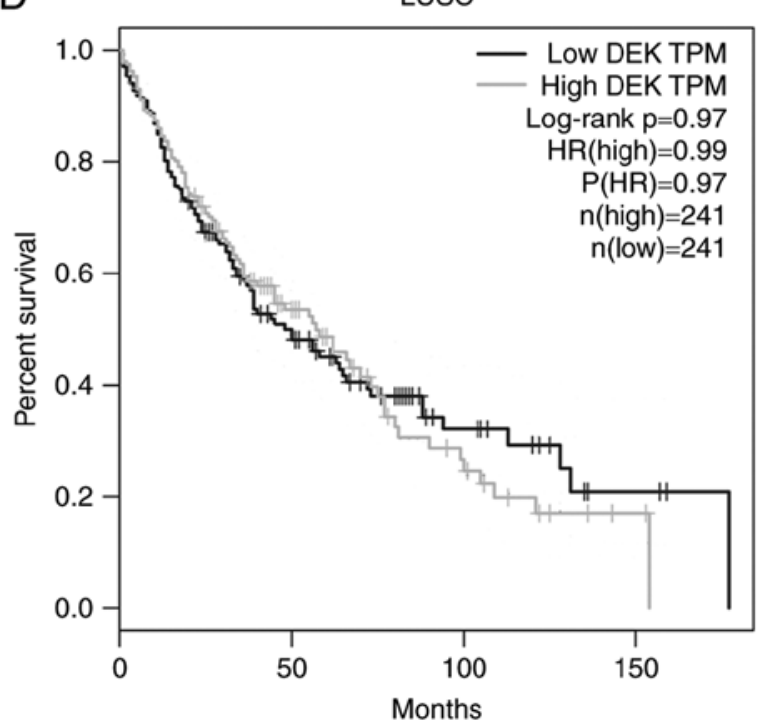

Figure 1. DEK expression in lung cancers and its correlation with the prognosis of lung cancers. DEK expression levels in (A) LUAD and (B) LUSC compared with that in normal lung tissues. Data were obtained from the UALCAN database. Kaplan-Meier plots of overall survival of patients with LUAD (C) and LUSC (D) stratified by DEK expression. Data were obtained from the GEPIA database. LUAD, lung adenocarcinoma; LUSC, lung squamous cell carcinoma; GEPIA, Gene Expression Profiling Interactive Analysis.

active- $\beta$-catenin, LEF1, cyclin D1, c-Myc, and MMP7, and increased the expression of Gsk3 $\beta$ and Axin in H1299-ShDEK and A549-ShDEK cells $(\mathrm{P}<0.05)$. The expression levels of total $\beta$-catenin, DVL1, LRP6 and TCF4 were not markedly altered $(\mathrm{P}>0.05)$ (Fig. 5A-C).

DEK promotes EMT. The expression levels of vimentin, Snail, and N-cadherin were increased, while E-cadherin was decreased in H1299-DEK and A549-DEK cells $(\mathrm{P}<0.05)$ (Fig. 4D-F). Conversely, in H1299-shDEK and A549-shDEK cells, the expression levels of vimentin, Snail, and N-cadherin were decreased, while E-cadherin was significantly increased $(\mathrm{P}<0.05)$ (Fig. 5D-F).

DEK expression is correlated with the levels of EGFR and $K R A S$ in lung adenocarcinomas. According to the data from the GEPIA database, the expression of DEK was correlated with the expression of EGFR and KRAS $(\mathrm{P}<0.001$, respectively), but was not correlated with the expression of ALK $(\mathrm{P}=0.82)$ or c-ros oncogene 1 receptor kinase (ROS1) $(\mathrm{P}=0.40)$ in LUADs (Fig. 6). In LUSCs, DEK expression was not correlated with the expression of EGFR ( $\mathrm{P}=0.46), \mathrm{KRAS}$ $(\mathrm{P}=0.061)$, ALK $(\mathrm{P}=0.82)$, or ROS1 $(\mathrm{P}=0.053)$ (Fig. 7). It was revealed by western blot analysis that enhanced DEK expression promoted the expression levels of EGFR and KRAS in H1299-DEK and A549-DEK cells $(\mathrm{P}<0.05$ in both cases), however, the level of ALK was not markedly altered (P>0.05) (Fig. 4D-F). Conversely, knockdown of DEK expression downregulated the levels of EGFR and KRAS in H1299-shDEK and A549-shDEK cells ( $\mathrm{P}<0.05$, respectively), however the level of ALK was not markedly altered $(\mathrm{P}>0.05)$ (Fig. 5D-F).

\section{Discussion}

$D E K$ is located on chromosome 6, consists of 11 exons and is controlled by a TATA-less promoter that contains a $\mathrm{CpG}$ island around the transcriptional start and several binding sites for transcription factors (15). $D E K$ was first isolated as part of a fusion that arises in a subtype of acute myeloid leukemias involving the $(6,9)$ chromosomal translocation (28). $D E K$ regulates hematopoiesis by increasing the repopulating 

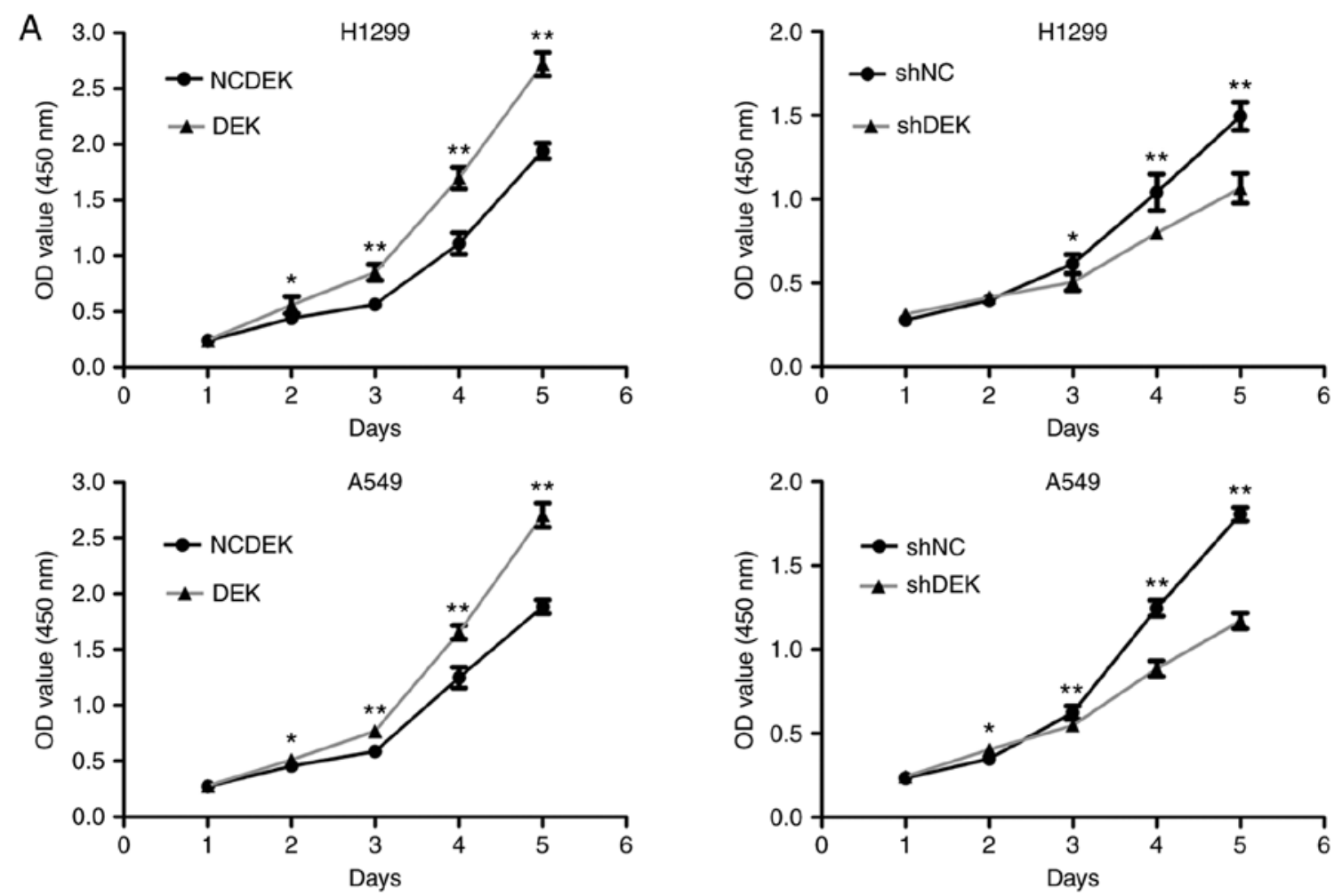

B
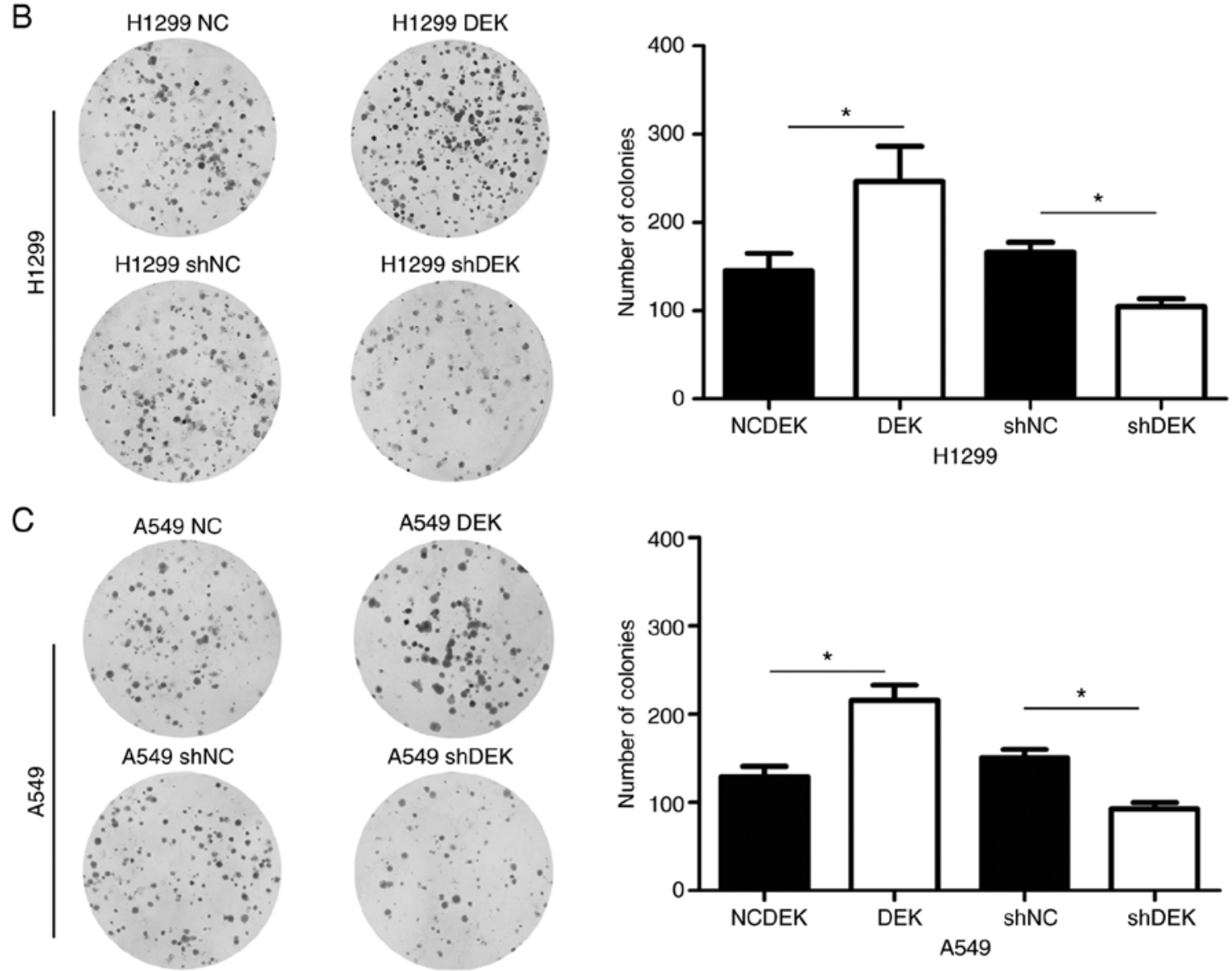

Figure 2. Effect of DEK on proliferation and colony formation of lung cancer cells. The (A) CCK-8 cell proliferation assay and (B and C) colony formation assay (x200) were performed after $D E K$ transfection or shRNA interference in $\mathrm{H} 1299$ and A549 cells. " $\mathrm{P}<0.05,{ }^{* *} \mathrm{P}<0.01$. CCK-8, Cell Counting Kit-8; NC, negative control cells; DEK, cells transfected with DEK; shNC, cells transfected with scrambled shRNA; shDEK, cells transfected with DEK-shRNA.

and self-renewal capacity of hematopoietic stem cells while decreasing the number and cycling of hematopoietic progenitor cells (29). $D E K$ has been reported as an oncogene in breast, cervical, and neuroendocrine prostate cancer, 


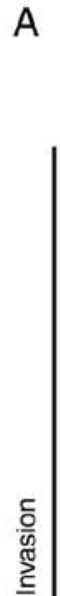

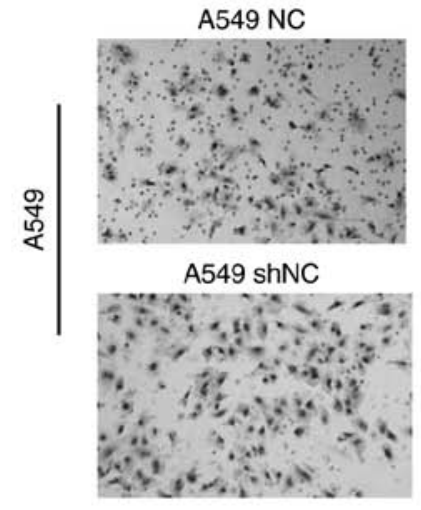

B

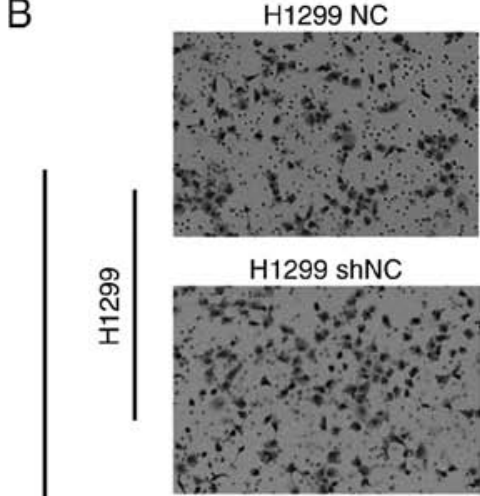

든

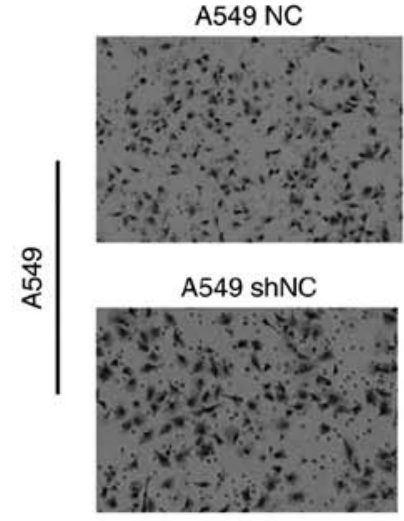

H1299 DEK

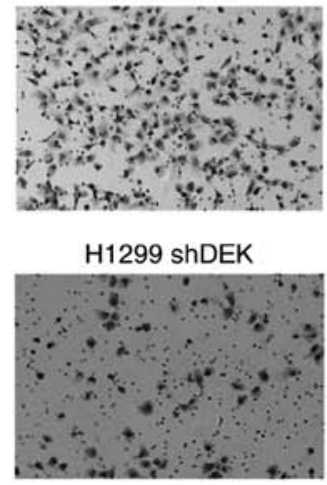

A549 DEK

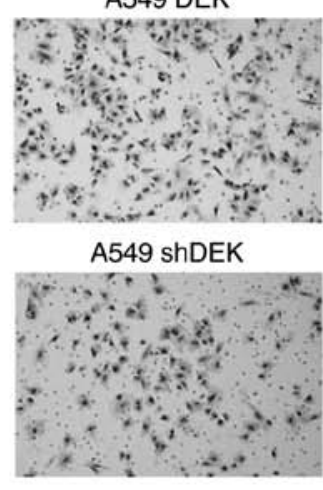

H1299 DEK

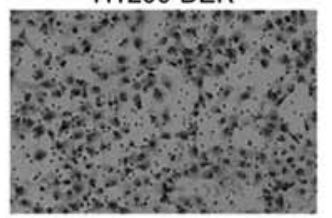

H1299 shDEK

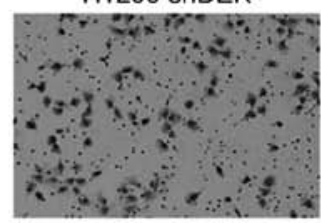

A549 DEK

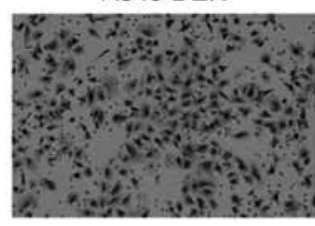

A549 shDEK

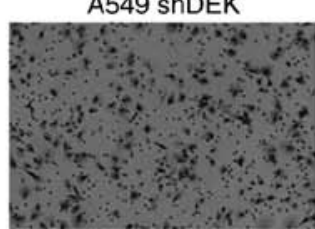

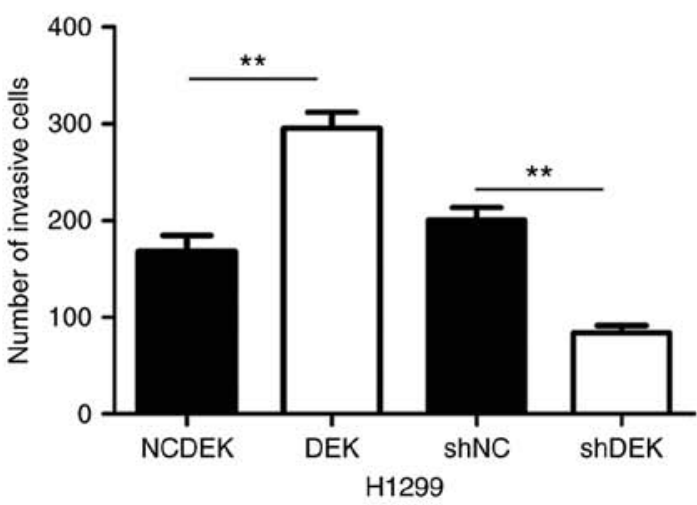
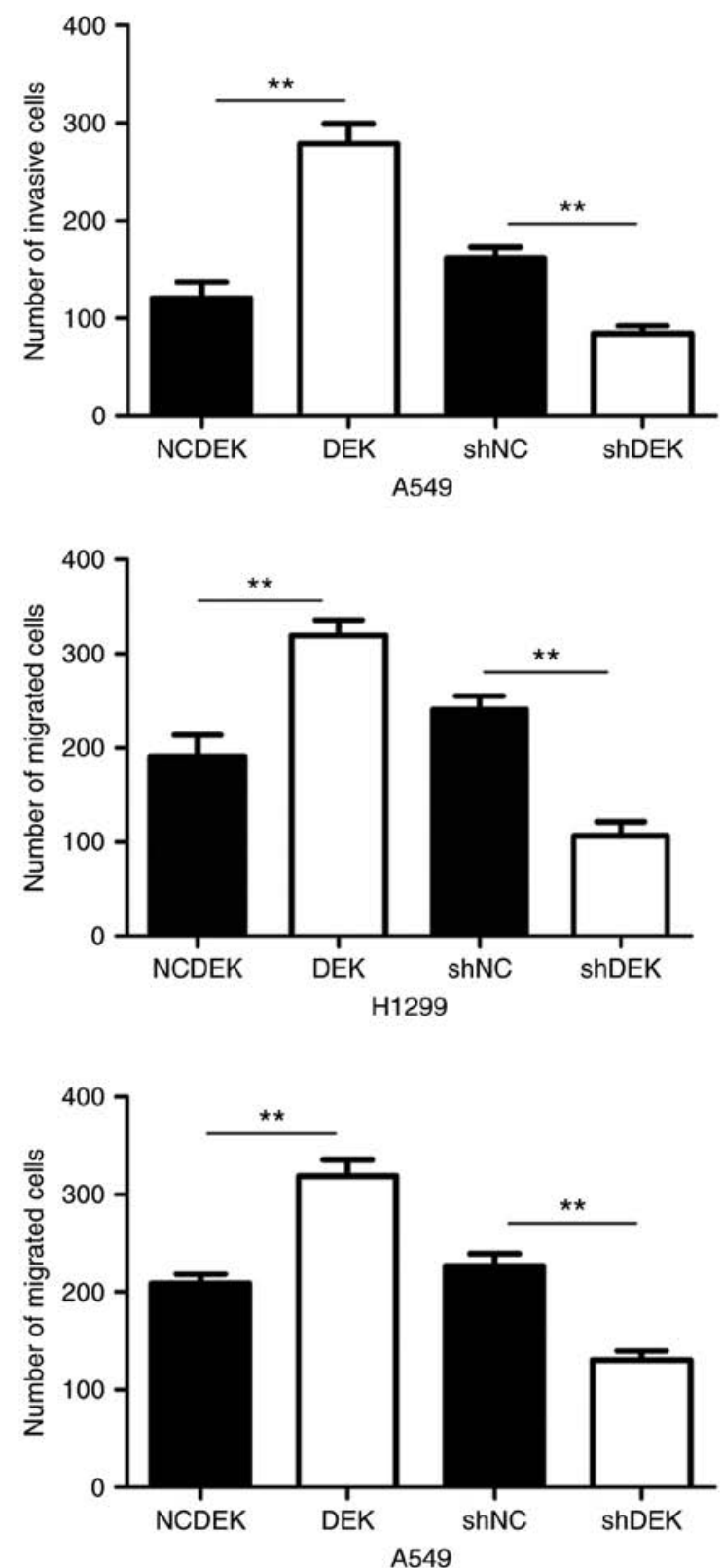

Figure 3. Effects of DEK on the invasion and migration of lung cancer cells. (A) Transwell invasion (x200) and (B) migration (x200) assays were performed after $D E K$ transfection or shRNA interference in $\mathrm{H} 1299$ and A549 cells. ${ }^{* *} \mathrm{P}<0.01$. NC, negative control cells; DEK, cells transfected with DEK; shNC, cells transfected with scrambled shRNA; shDEK, cells transfected with DEK-shRNA.

acute myeloid leukemia, gastric adenocarcinoma, and lung cancer $(8,18,20-23,30)$.
Previous studies have documented the expression of DEK in NSCLC $(18,20,25)$, which indicated that DEK expression 

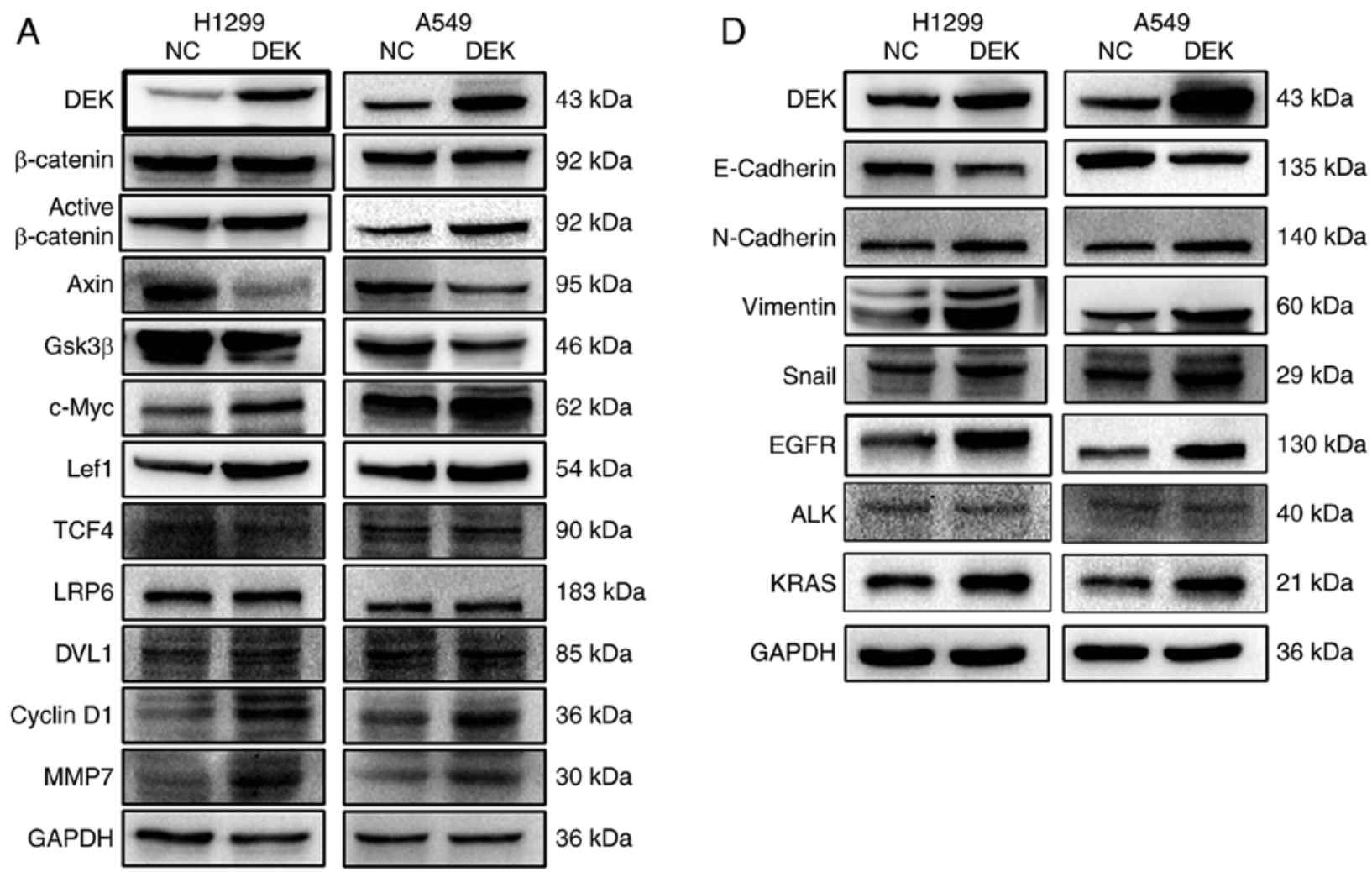

B
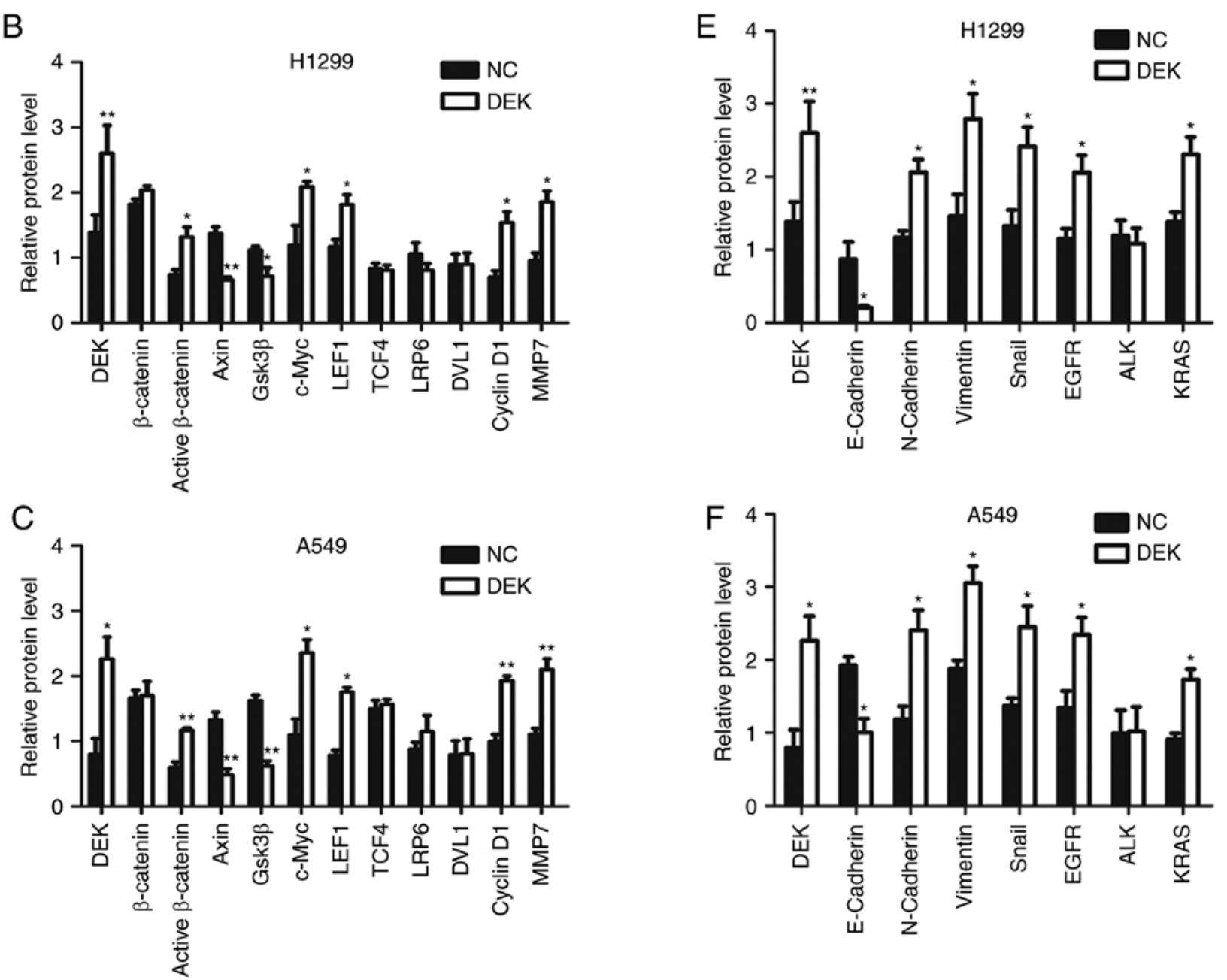

Figure 4. Expression of Wnt and EMT-related proteins, EGFR, KRAS, and ALK after forced upregulation of DEK in lung cancer cells. Representative results of (A and D) western blot analysis, and histograms of relative protein levels in (B and E) H1299 cells and (C and F) A549 cells. GAPDH served as an internal control. ${ }^{*} \mathrm{P}<0.05,{ }^{* *} \mathrm{P}<0.01$. EGFR, epidermal growth factor receptor; KRAS, Kirsten rat sarcoma viral oncogene homolog; ALK, anaplastic lymphoma kinase; NC, negative control cells; DEK, cells transfected with DEK. 


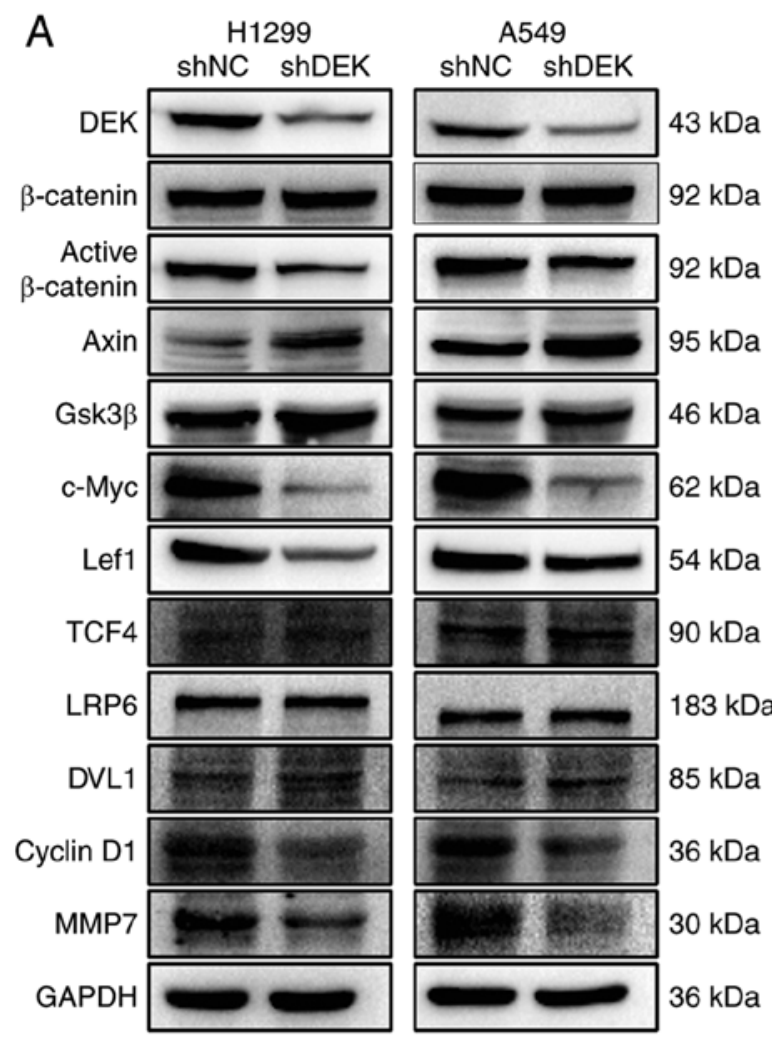

B

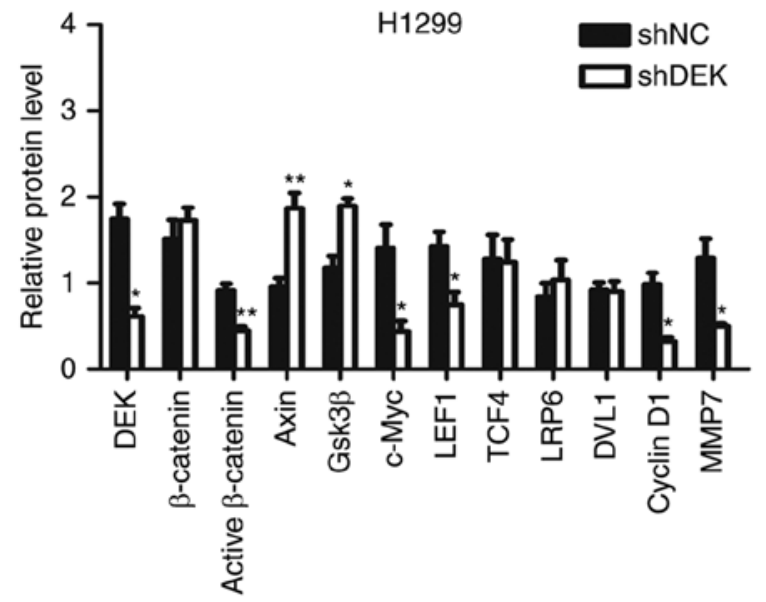

C

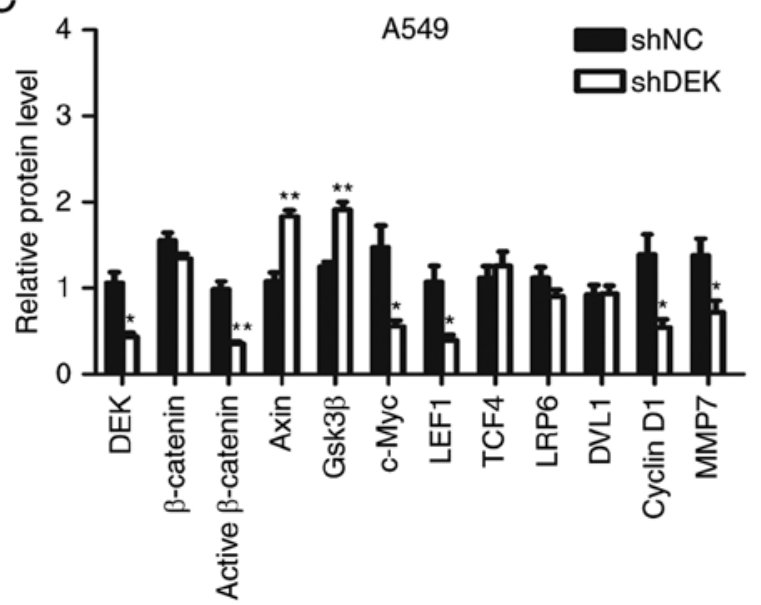

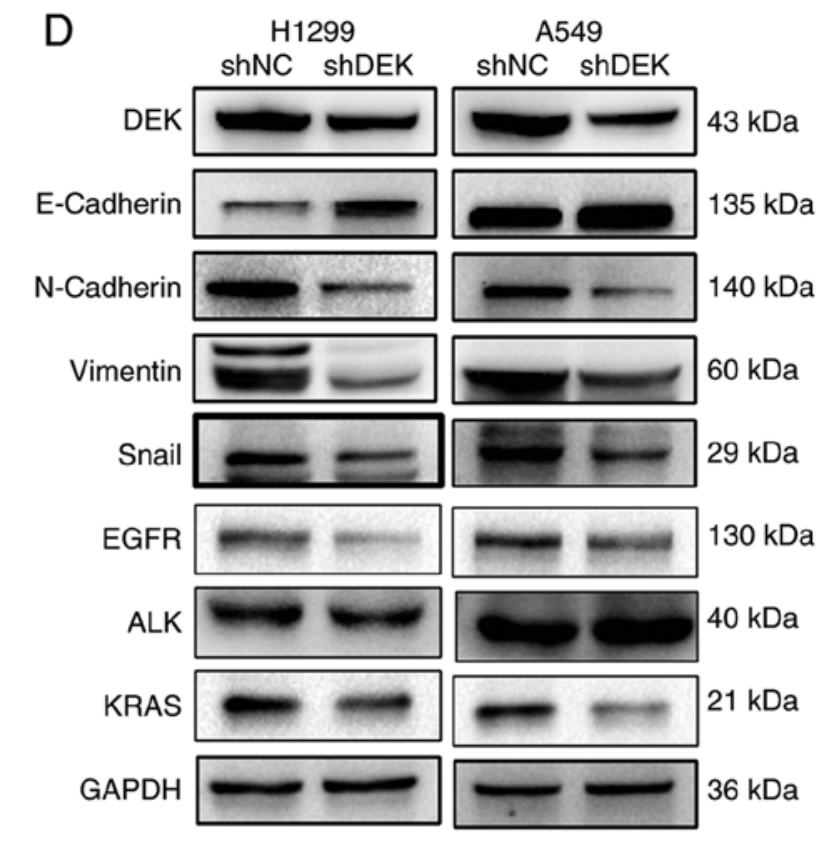
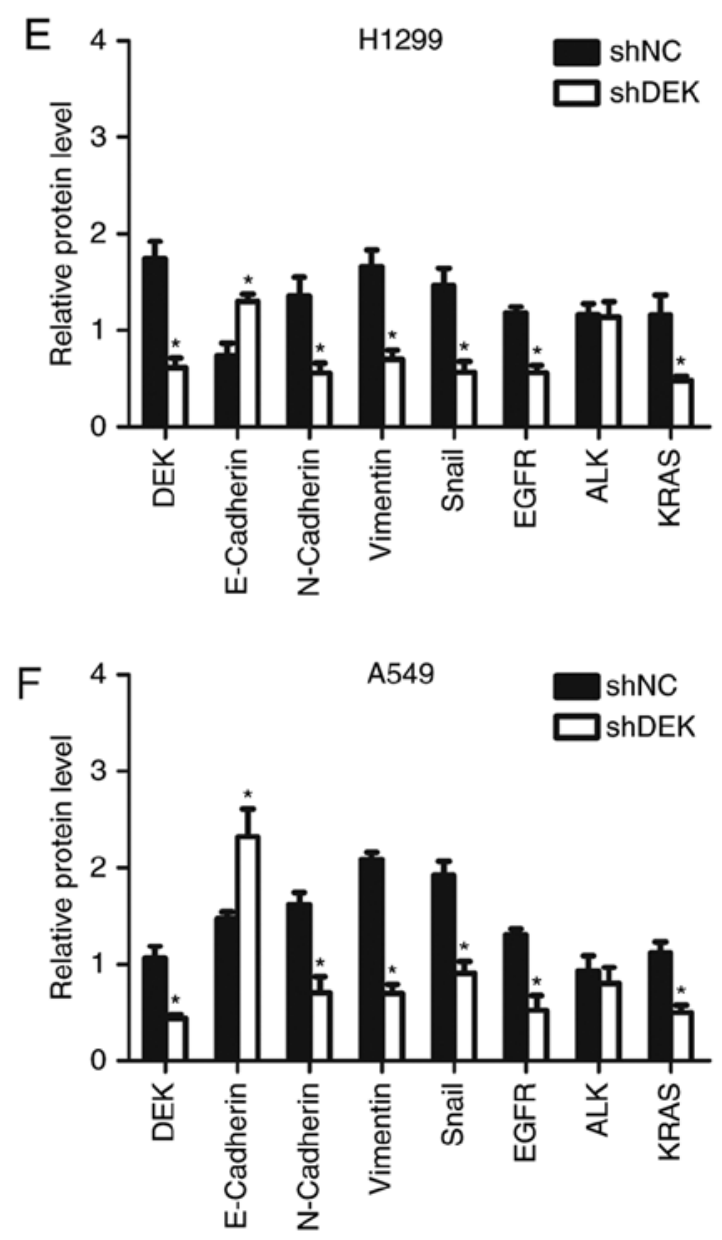

Figure 5. Expression of Wnt and EMT-related proteins, EGFR, KRAS, and ALK after forced downregulation of DEK in lung cancer cells. Representative results of (A and D) western blot analysis, and histograms of relative protein levels in (B and E) H1299 cells and (C and F) A549 cells. GAPDH served as an internal control. ${ }^{*} \mathrm{P}<0.05,{ }^{* *} \mathrm{P}<0.01$. EGFR, epidermal growth factor receptor; KRAS, Kirsten rat sarcoma viral oncogene homolog; ALK, anaplastic lymphoma kinase; shNC, cells transfected with scrambled shRNA; shDEK, cells transfected with DEK-shRNA. 
A

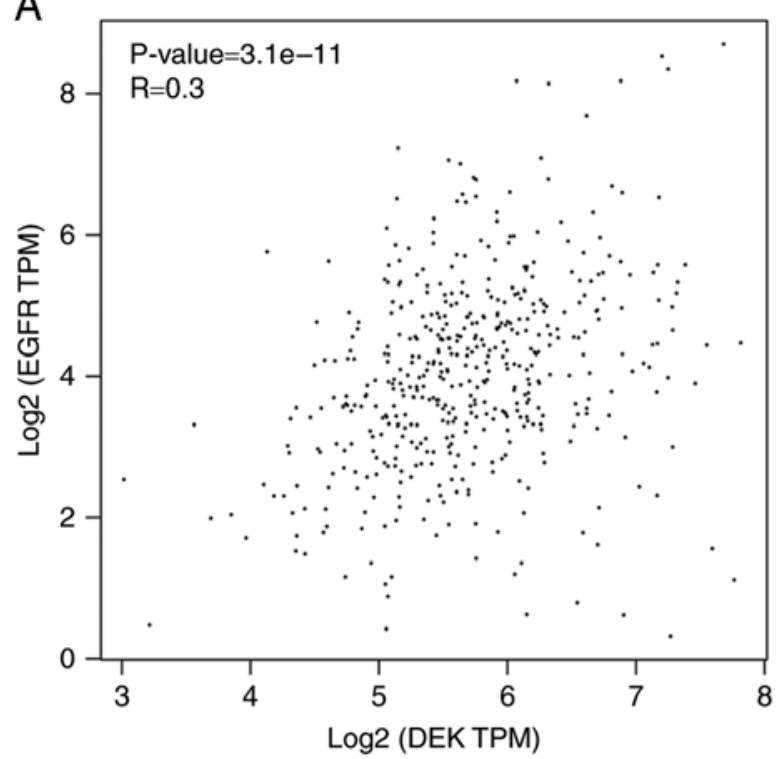

C

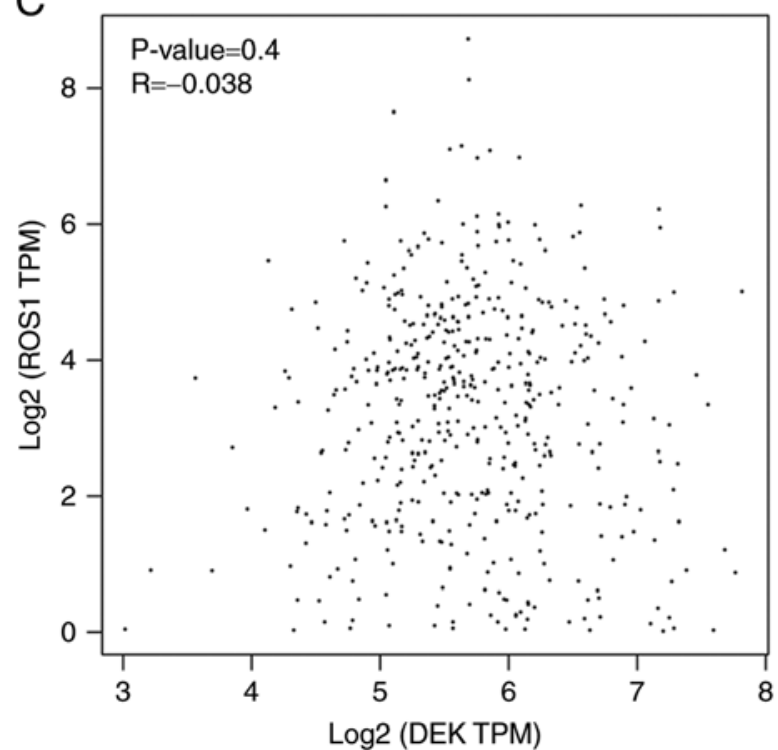

B
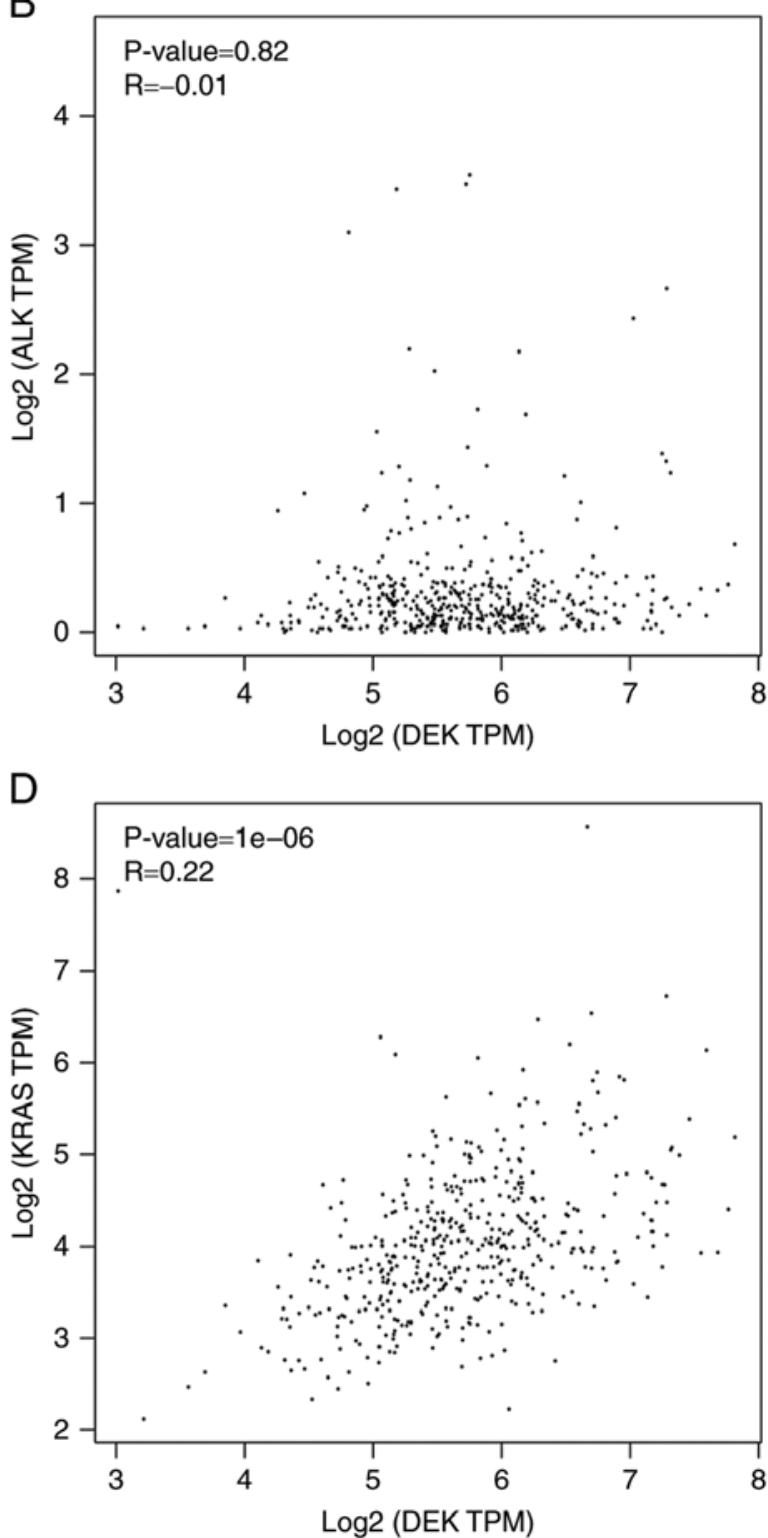

Figure 6. Correlations between DEK and EGFR, ALK, ROS1, and KRAS in LUAD. The scatter diagrams that display correlations between DEK and (A) EGFR, (B) ALK, (C) ROS1, and (D) KRAS in LUADs were obtained from GEPIA. EGFR, epidermal growth factor receptor; ALK, anaplastic lymphoma kinase; ROS1, c-ros oncogene 1 receptor kinase; KRAS, Kirsten rat sarcoma viral oncogene homolog; LUAD, lung adenocarcinoma; GEPIA, Gene Expression Profiling Interactive Analysis.

was correlated with the progression of NSCLCs. However, the effect and mechanism of DEK underlying the progression and prognosis of NSCLCs still requires further investigation. In the present study, by analyzing the data from TCGA, it was confirmed that DEK was prominently overexpressed in NSCLCs, when compared to DEK expression in normal lung tissues, and that an increased DEK level predicted poor prognosis in LUAD patients. Furthermore, DEK expression was correlated with EGFR, KRAS in LUAD. EGFR is a common therapeutic target in NSCLCs (31-33). Therefore, it is possible that DEK is involved in the mechanism of gene target therapy. The level of DEK may be a predictive indicator of the therapeutic effect of gene-targeted drugs, which require further investigation.

The mechanisms by which DEK promotes the proliferation and invasion of lung cancers are poorly investigated. A study by Wang et al reported that DEK depletion downregulated RhoA expression and indicated that DEK inhibited cell migration by inactivation of the RhoA/ROCK/MLC signaling pathway (25). To explore the regulating mechanisms of DEK in NSCLCs, the effects of DEK on the Wnt signaling pathway and EMT were examined. The results revealed that DEK expression upregulated the levels of active $\beta$-catenin and Wnt target genes, such as cyclin D1, c-Myc and MMP7. Furthermore, DEK expression activated the EMT process by decreasing the expression of E-cadherin, and enhancing the expression of $\mathrm{N}$-cadherin, vimentin, and Snail. The Wnt pathway is important in embryonic development and is involved in the development of many cancers $(34,35)$. The present results indicated that DEK promoted the proliferation and invasion of NSCLC and activated the Wnt signaling pathway and EMT process. In the present study, it was also 

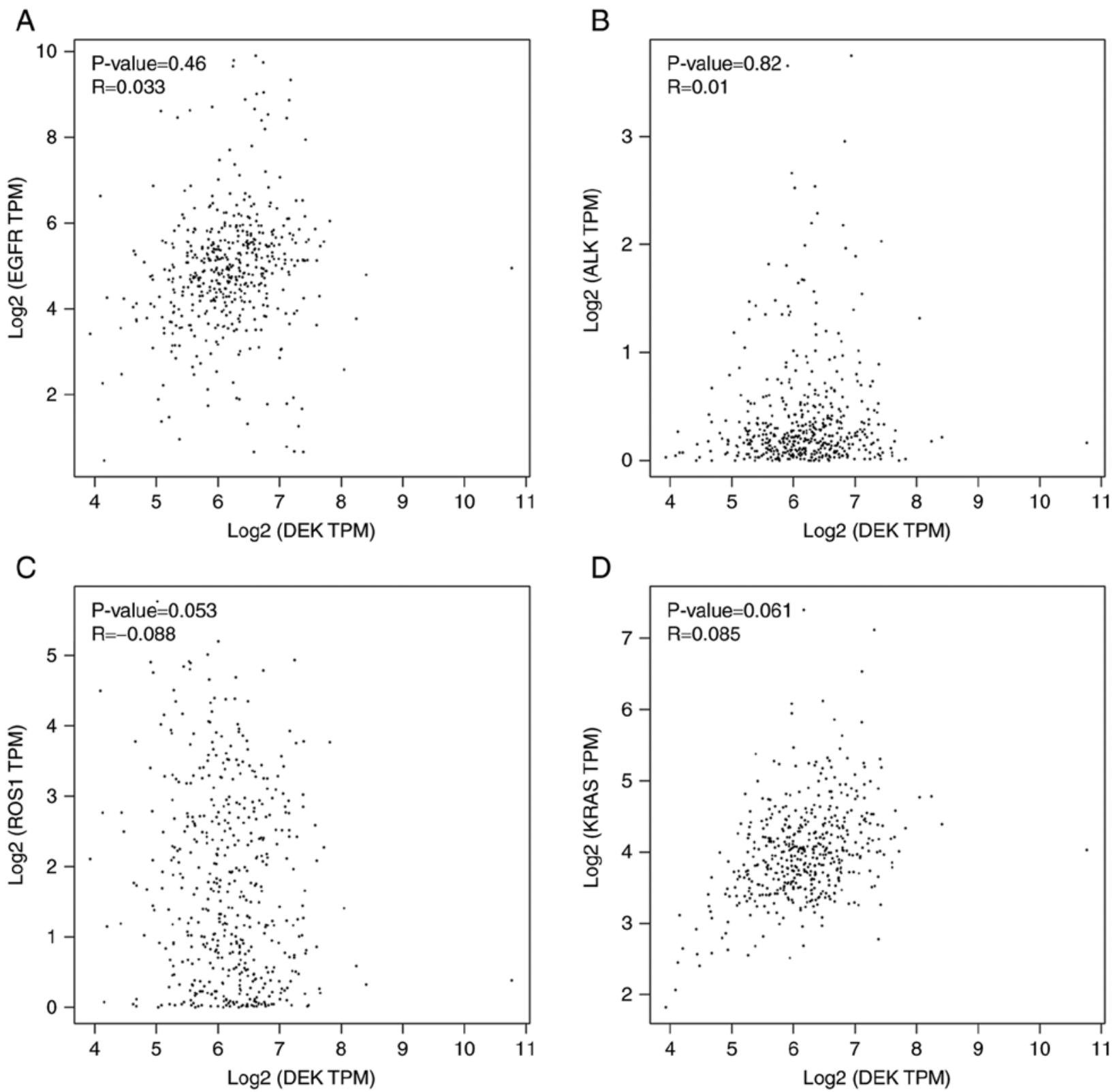

Figure 7. Correlations between DEK and EGFR, ALK, ROS1, and KRAS in LUSC. The scatter diagrams that display correlations between DEK and (A) EGFR, (B) ALK, (C) ROS1, and (D) KRAS in LUSCs were obtained from GEPIA. EGFR, epidermal growth factor receptor; ALK, anaplastic lymphoma kinase; ROS1, c-ros oncogene 1 receptor kinase; KRAS, Kirsten rat sarcoma viral oncogene homolog; LUSC, lung squamous cell carcinoma; GEPIA, Gene Expression Profiling Interactive Analysis.

observed that DEK did not regulate the total expression level of $\beta$-catenin, but regulated only the expression level of active $\beta$-catenin. In addition, DEK overexpression downregulated the levels of Gsk3 $\beta$ and Axin, which are key proteins of the Gsk3/Axin/APC complex inducing the phosphorylation and degradation of $\beta$-catenin. Thus, DEK may enhance the activity of $\beta$-catenin by regulating the Gsk3 $\beta /$ Axin/APC complex, which requires further confirmation.

In conclusion, DEK was revealed to be overexpressed in lung cancers, which indicated poor prognosis in lung adenocarcinomas. Overexpression of DEK activated the Wnt signaling pathway and EMT process, and promoted the proliferation and invasion of lung cancers. DEK is a potential prognostic biomarker,and a potential target of gene therapy for NSCLC.

\section{Acknowledgements}

Not applicable.

\section{Funding}

The present study was supported by the National Natural Science Foundation of China (grant no. 81372497 to HTX) and Program for Liaoning Excellent Talents in University (grant no. LR2015067 to HTX).

\section{Availability of data and material}

The data supporting the conclusions of this article are included within the article and its supplementary information files. 


\section{Authors' contributions}

HTX designed the study. MQY and HTX participated in drafting the manuscript. MQY, LLB, LL, YWZ, ZW, ZHL, $\mathrm{CCL}$ and WJH performed the experiments. All authors have read and approved the final version of this manuscript.

\section{Ethics approval and consent to participate}

Not applicable.

\section{Patient consent for publication}

Not applicable.

\section{Competing interests}

The authors declare that they have no competing interests.

\section{References}

1. DeSantis CE, Miller KD, Goding Sauer A, Jemal A and Siegel RL: Cancer statistics for African Americans, 2019. CA Cancer J Clin 69: 211-233, 2019.

2. Li J, Guo W, Ran J, Tang R, Lin H, Chen X, Ning B, Li J, Zhou Y, Chen LC, et al: Five-year lung cancer mortality risk analysis and topography in Xuan Wei: A spatiotemporal correlation analysis. BMC Public Health 19: 173, 2019.

3. Barta JA, Powell CA and Wisnivesky JP: Global epidemiology of lung cancer. Ann Glob Health 85: 8, 2019.

4. Nedović-Vuković M, Laušević D, Ljaljević A, Golubović M and Trajković G: Lung cancer mortality in Montenegro, 1990 to 2015. Croat Med J 60: 26-32, 2019

5. Haas K, Brillante C, Sharp L, Elzokaky AK, Pasquinelli M, Feldman L, Kovitz KL and Joo M: Lung cancer screening: assessment of health literacy and readability of online educational resources. BMC Public Health 18: 1356, 2018.

6. Oze I, Ito H, Nishino Y, Hattori M, Nakayama T, Miyashiro I, Matsuo $\mathrm{K}$ and Ito Y: Trends in small-cell lung cancer survival in 1993-2006 based on population-based cancer registry data in Japan. J Epidemiol 29: 347-353, 2019.

7. Riveiro-Falkenbach E, Ruano Y, Garcia-Martin RM, Lora D, Cifdaloz M, Acquadro F, Ballestín C, Ortiz-Romero PL, Soengas MS and Rodríguez-Peralto JL: DEK oncogene is overexpressed during melanoma progression. Pigment Cell Melanoma Res 30: 194-202, 2017.

8. Yang Y, Gao M, Lin Z, Chen L, Jin Y, Zhu G, Wang Y and Jin T: DEK promoted EMT and angiogenesis through regulating PI3K/AKT/mTOR pathway in triple-negative breast cancer. Oncotarget 8: 98708-98722, 2017.

9. Lin D, Dong X, Wang K, Wyatt AW, Crea F, Xue H, Wang Y, Wu R, Bell RH, Haegert A, et al: Identification of DEK as a potential therapeutic target for neuroendocrine prostate cancer. Oncotarget 6: 1806-1820, 2015.

10. Waldmann T, Scholten I, Kappes F, Hu HG and Knippers R: The DEK protein-an abundant and ubiquitous constituent of mammalian chromatin. Gene 343: 1-9, 2004.

11. Fu GK, Grosveld G and Markovitz DM: DEK, an autoantigen involved in a chromosomal translocation in acute myelogenous leukemia, binds to the HIV-2 enhancer. Proc Natl Acad Sci USA 94: 1811-1815, 1997.

12. Kappes F, Scholten I, Richter N, Gruss C and Waldmann T: Functional domains of the ubiquitous chromatin protein DEK Mol Cell Biol 24: 6000-6010, 2004.

13. Matrka MC, Watanabe M, Muraleedharan R, Lambert PF, Lane AN, Romick-Rosendale LE and Wells SI: Overexpression of the human DEK oncogene reprograms cellular metabolism and promotes glycolysis. PLoS One 12: e0177952, 2017.
14. Böhm F, Kappes F, Scholten I, Richter N, Matsuo H, Knippers R and Waldmann T: The SAF-box domain of chromatin protein DEK. Nucleic Acids Res 33: 1101-1110, 2005.

15. Kappes F, Burger K, Baack M, Fackelmayer FO and Gruss C: Subcellular localization of the human proto-oncogene protein DEK. J Biol Chem 276: 26317-26323, 2001.

16. Waldmann T, Eckerich C, Baack M and Gruss C: The ubiquitous chromatin protein DEK alters the structure of DNA by introducing positive supercoils. J Biol Chem 277: 24988-24994, 2002.

17. Sandén C and Gullberg U: The DEK oncoprotein and its emerging roles in gene regulation. Leukemia 29: 1632-1636, 2015.

18. Xu Y, Liang Z, Li C, Yang Z and Chen L: LCMR1 interacts with DEK to suppress apoptosis in lung cancer cells. Mol Med Rep 16: 4159-4164, 2017.

19. Boer J, Mahmoud H, Raimondi S, Grosveld G and Krance R: Loss of the DEK-CAN fusion transcript in a child with $\mathrm{t}(6 ; 9)$ acute myeloid leukemia following chemotherapy and allogeneic bone marrow transplantation. Leukemia 11: 299-300, 1997.

20. Zhou QC, Deng XF, Yang J, Jiang H, Qiao MX, Liu HH, Qian Z, Hou LL and Hu HG: Oncogene DEK is highly expressed in lung cancerous tissues and positively regulates cell proliferation as well as invasion. Oncol Lett 15: 8573-8581, 2018.

21. Ou Y, Xia R, Kong F, Zhang X, Yu S, Jiang L, Zheng L and Lin L: Overexpression of DEK is an indicator of poor prognosis in patients with gastric adenocarcinoma. Oncol Lett 11: 1823-1828, 2016.

22. Xu X, Zou L, Yao Q, Zhang Y, Gan L and Tang L: Silencing DEK downregulates cervical cancer tumorigenesis and metastasis

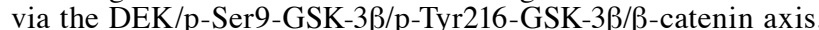
Oncol Rep 38: 1035-1042, 2017.

23. Liu K, Feng T, Liu J, Zhong M and Zhang S: Silencing of the DEK gene induces apoptosis and senescence in CaSki cervical carcinoma cells via the up-regulation of NF- $\kappa \mathrm{B}$ p65. Biosci Rep 32: 323-332, 2012.

24. Chandrashekar DS, Bashel B, Balasubramanya SAH, Creighton CJ, Ponce-Rodriguez I, Chakravarthi BVSK and Varambally S: UALCAN: A portal for facilitating tumor subgroup gene expression and survival analyses. Neoplasia 19: 649-658, 2017.

25. Wang J, Sun L, Yang M, Luo W, Gao Y, Liu Z, Qiu X and Wang E: DEK depletion negatively regulates Rho/ROCK/MLC pathway in non-small cell lung cancer. J Histochem Cytochem 61: 510-521, 2013.

26. Wang Y, Lei L, Zheng YW, Zhang L, Li ZH, Shen HY, Jiang GY, Zhang XP, Wang EH and Xu HT: Odd-skipped related 1 inhibits lung cancer proliferation and invasion by reducing Wnt signaling through the suppression of SOX9 and $\beta$-catenin. Cancer Sci 109: 1799-1810, 2018.

27. Lei L, Wang Y, Zheng YW, Fei LR, Shen HY, Li ZH, Huang WJ, Yu JH and Xu HT: Overexpression of Nemo-like kinase promotes the proliferation and invasion of lung cancer cells and indicates poor prognosis. Curr Cancer Drug Targets 19: 674-680, 2019.

28. Soekarman D, von Lindern M, van der Plas DC, Selleri L, Bartram CR, Martiat P, Culligan D, Padua RA, Hasper-Voogt KP, Hagemeijer A, et al: Dek-can rearrangement in translocation (6;9)(p23;q34). Leukemia 6: 489-494, 1992.

29. Capitano ML and Broxmeyer HE: A role for intracellular and extracellular DEK in regulating hematopoiesis. Curr Opin Hematol 24: 300-306, 2017.

30. Sandén C, Nilsson HJ and Gullberg U: The DEK oncoprotein is upregulated by multiple leukemia-associated fusion genes. Blood Cells Mol Dis 54: 284-285, 2015

31. Diaz-Serrano A, Gella P, Jimenez E, Zugazagoitia J and Paz-Ares Rodriguez L: Targeting EGFR in lung cancer: Current standards and developments. Drugs 78: 893-911, 2018.

32. Jurišić V, Obradovic J, Pavlović S and Djordjevic N: Epidermal growth factor receptor gene in non-small-cell lung cancer: The importance of promoter polymorphism investigation. Anal Cell Pathol (Amst) 2018: 6192187, 2018.

33. Bernicker EH, Allen TC and Cagle PT: Update on emerging biomarkers in lung cancer. J Thorac Dis 11 (Suppl 1): S81-S88, 2019.

34. van Neerven SM and Vermeulen L: The interplay between intrinsic and extrinsic Wnt signaling in controlling intestinal transformation. Differentiation 108: 17-23, 2019.

35. Schaefer KN and Peifer M: Wnt/Beta-catenin signaling regulation and a role for biomolecular condensates. Dev Cell 48: 429-444, 2019. 